\title{
Use of waste powder coatings as binders for the manufacture of composite materials
}

\author{
A. C. Abhyankar, N. R. Edmonds \& A. J. Easteal \\ Chemistry Department and Centre for Advanced Composite Materials, \\ The University of Auckland, New Zealand
}

\begin{abstract}
Powder coatings are $100 \%$ solid dry powders that are used to coat a wide variety of substrates. They are considered an environmentally friendly coating option with no volatile emissions and minimal overspray wastage. Fines $(5 \%$ of the powder manufactured) that are not fit for application are also generated during production. Reworking them into usable powder is a costly and cumbersome process and hence they are not reclaimed. For this study three powder coating thermosetting powders were selected. Composites were made by using waste powder coating powders (WPCP) and fines as a primary binder, along with secondary binders and sawdust as the reinforcing material. Scanning electron microscopy (SEM) and differential scanning calorimetry (DSC) were used to characterise composite boards formed using compressive moulding. The composite boards resemble particle boards and were tested for their mechanical properties according to the prescribed standard (AS/NZS 1895.1:2004 for Reconstituted Wood Based Panels). All results confirmed that the composite boards had mechanical performances comparable with conventional commercial boards. As they are constructed wholly from industrial waste materials these particle boards are novel products, and commercialization of this industrial ecological product is envisioned.

Keywords: powder coatings, waste, fines, composites, particleboards, physical and mechanical properties, SEM, thermal analysis, DSC.
\end{abstract}

\section{Introduction}

Powder coatings are a dry powder paint technology used to coat a wide variety of conductive substrates, ranging from metals to specially treated wood. They 
are environmentally friendly coatings as there are no volatile emissions and wastage is small; even overspray material can be reused when coating application is of a single colour. Their environmental acceptability and other advantages ensure their continuing success, but there are some problems to be solved. At the applicators end, recycling of over sprayed powder minimises waste, but in a multicoloured commercial system it is often cheaper to spray to waste. In many of these installations, huge quantities of powder coatings are sprayed once, lost into the recovery system, mixed with all other over sprayed materials, and then packaged for disposal. About 5 to $15 \%$ of total powder sprayed by applicators is collected as waste. When different colours are sprayed the amount wasted is higher and is referred to as waste powder coating powder (WPCP). In addition to overspray resulting from powder application, fines generated during powder production provide further waste. At the manufacturers stage powders with a particle size less than about $10 \mu \mathrm{m}$ cannot be sold as they currently have unsuitable application and film-forming characteristics, and reworking them into usable powder is a costly and cumbersome process. These fines are a mixture of powder coating formulations collected at regular intervals in the bag house, and about $5 \%$ of total production is collected as such fines. Other reasons for increased quantities of waste are the incompatibility of powder coating particles taken from different batches using the same formulation and raw materials, colour matching rejects and old stock. Production failures may also add to the waste.

Recent work by Graewe [1], Kilner [2], Blatter et al [3] and others have resulted in patents on the re-incorporation of fines into new manufactured powder. Some attempts have also been made to use the waste powder and fines in insulating blocks as reported by Murray [4] and as a slurry (Anon [5]) to be used as paint. However, reprocessing the fines to a suitable particle size is not economically viable, and the fines are disposed of as a waste stream. This is not an ideal solution because it is an additional cost moreover, there are environmental concerns regarding certain coating powders.

The waste materials are chemically reactive polymers and as such are valuable raw material that can be utilized in developing commercial products. In this study only thermosetting powder coatings were considered. These include epoxy, polyester and hybrid powders based on lower molecular weight solid resins with different chemistries. When subjected to elevated temperatures, these coatings melt, flow and chemically crosslink within themselves or with other reactive components to form a higher molecular weight reaction product.

The aim of this research was to make use of the WPCP and fines as a binder in making composite panelboards. It was envisioned that the product should be unique, commercially viable, and appealing in utilising the current annual world powder manufacturing waste estimate of 60,000 tonnes $(5 \%$ of an estimated production of 1,200,000 tonnes (Wright [6]) for 2007) plus an additional 5 to $15 \%$ of the sprayed waste. Composite production and product characteristics are discussed in this paper. 


\section{Materials}

\subsection{Powders as primary binder}

For this study three powder chemistries were used:

- Polyester (carboxyl functional) powders cured with TGIC (triglycidyl isocyanurate).

- Polyester (carboxyl functional) powders cured with HAA ( $\beta$ hydroxyl alkyl amide), referred to as Primid.

- Hybrid powders (carboxyl functional polyesters cured with epoxy resins based on bisphenol A).

- The fines (small particle size powders) collected from the bag house being a mixture of the powder chemistries currently in production.

\subsection{Sawdust as the reinforcing matrix}

Sawdust (of Pinus radiata) with particle size less than $3 \mathrm{~mm}$, half of which was in the range $1-2 \mathrm{~mm}$, and moisture content about $5 \%$, was the reinforcing material. The sawdust constituted $50 \%$ of the composite mixture by weight, and sawdust from the same source was used for production of all composite boards to minimise variations in product properties due to variability of sawdust characteristics.

\subsection{Other industrial polymer waste as the secondary binder}

A VOC-free industrial liquid polymer waste of known composition was used as a secondary binder. It consisted of $50 \%$ solids by weight. It should be noted that waste polymer disposal of that material is of concern in itself. For this study a single type of liquid polymer waste was used to minimise variations in product properties from that source.

\section{Experimentation}

Mixing the sawdust with the binders was done manually for the first set of experiments, and different mixing methods in the second set of experiments. The efficiency of mixing as reflected in the homogeneity of the mixtures was dependent on the method of mixing.

Composite boards with dimensions $310 \times 250 \mathrm{~mm}$ were pre-formed in a wooden mould by cold pressing the composite mixture for three minutes under a pressure of $150 \mathrm{kPa}$ using a 100 ton hydraulic press. The mould was then dismantled and the composite pre-form hot pressed at $160^{\circ} \mathrm{C}$ in a 50 ton hydraulic press for ten minutes with the use of $3 \mathrm{MPa}$ pressure. A $12 \mathrm{~mm}$ mechanical stop was used to control the thickness of the boards. The target density was $900-950 \mathrm{~kg} \mathrm{~m}^{-3}$. The composite mixture had a moisture content of about $12 \%$. The composites were made with sawdust: binder weight ratio of 50:50; where the binder component was a combination of the primary and 
secondary binders. Except for the type of powder the compositions were the same for all of the boards, which were all made in exactly the same way so that valid comparisons could be made of binder, binder efficiency and the effect of the method of mixing.

\subsection{Physical and mechanical properties}

For each board type three boards were made and cut to make test specimens with appropriate sizes whose physical and mechanical properties were determined according to the AS/NZS 1895.1:2004 standard for reconstituted wood based panels with the tests from AS/NZS 4266 series of standards.

\subsubsection{Effect of powder chemistry}

The purpose of making boards from the four types of powder coating waste, namely TGIC cured, Primid cured, Hybrid (polyester with epoxy) powders and fines (mixed chemistry), was to establish whether all of the powder types could (or should) be utilised independently, and whether the fines alone were satisfactory binders in imparting the desired board properties.

\subsubsection{Effect of mixing on board properties}

It is known[7] that the method of mixing raw materials can affect the properties of composites made from the raw material mixtures. To ascertain the effect of mixing procedure, the composite mixture was mixed by four methods, namely manually, and with a Mixaco mixer, screw extruder and ribbon blender. Boards were made using only the Primid powders for valid comparisons.

\subsection{Composite inter-phase characterization}

The fibre resin inter-phase was studied using scanning electron microscopy, and differential scanning calorimetry was used to characterise the curing process for both the powders and their respective composites.

\section{Results and discussion}

\subsection{Physical and mechanical properties}

All the boards were made using the same procedure (except for the method of mixing the raw materials) and the test results are tabulated and analysed below in relation to both binder efficiency and the effect of the mixing process.

\subsubsection{Effect of powder chemistry}

From the test results (Table 1) it is apparent that the test boards meet most of the specifications for the standard board, moisture resistant general purpose board and high performance particleboard, and that TGIC and Hybrid boards showed the best properties. The board thickness was close to the target thickness of 12 $\mathrm{mm}$, and the $24 \mathrm{~h}$ thickness swell data for the Hybrid and Fines boards are 
excellent. This suggests that the boards may be suitable for use in areas where they may be exposed to dampness. Physical examination of the boards revealed that most of the wood particles in the boards were coated with the binder and thus had greatly reduced propensity to absorb water, giving low moisture content for the boards. Overall the bending strength characteristics are good. Though the bending strengths (as represented by MOR) of the Primid and the Fines boards are lower than for the TGIC and Hybrid boards, they are close to the standard and can be said to be satisfactory. The internal bond strengths are all highly satisfactory in relation to the standard specifications. The modulus of elasticity of the boards was lower than expected.

\subsubsection{Type of mixing on board properties}

The appearance of boards (Figure 1) is directly related to the degree of homogeneity achieved by the mixing technique. The board made from manually mixed composite had patches of binder spread over the surface; the Mixaco mixer gave more homogeneity, though the board was still speckled. In the board made from screw extruder mixed composite the binder seemed to have very well coated the sawdust, resulting in a uniform appearance although the extrudate was granular and this was reflected in the appearance of the board. The board made from composite that was mixed in the ribbon blender showed the most homogeneous structure. It resulted in uniform mixing and a consistent appearance from batch to batch.

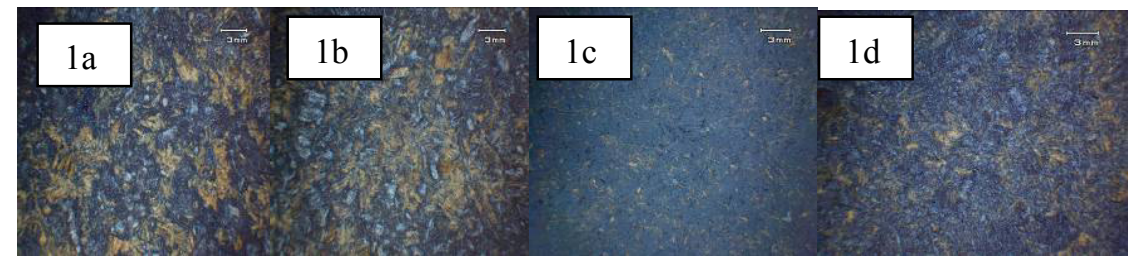

Figure 1: Visual appearances of boards made by (a), manual mixing; (b), Mixaco mixer; (c) screw extruder; (d), ribbon blender.

The effect of the method used for composite mixing on board properties is shown by the data shown in Table 2 and Figure 2. For this set of experiments all the boards were made with Primid powders.

The boards made from composite mixed using the twin screw extruder had the lowest strength (as measured by MOR), possibly because partial curing of the powder occurred as a result of a temperature increase arising from the high shear conditions in the extruder. Manual mixing and the Mixaco mixer gave relatively low MOR values of very similar magnitude due to non-uniform resin distribution. Manual mixing also gave comparatively high 24 hour water swell compared to the other boards. The boards made from composite mixed in the ribbon blender had the best overall properties. 


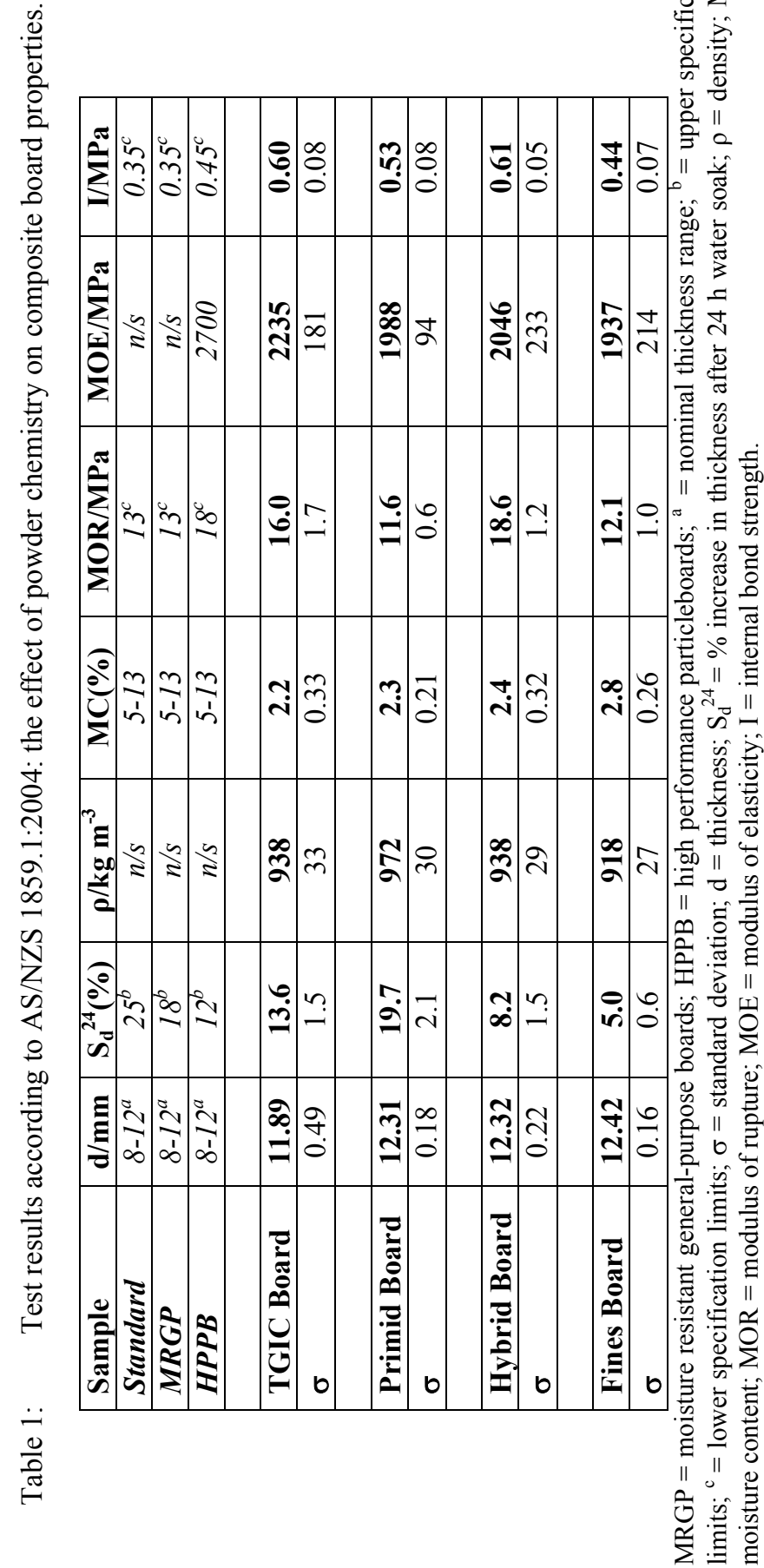

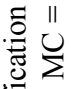
$\frac{2}{0}$ in o 矛 है 


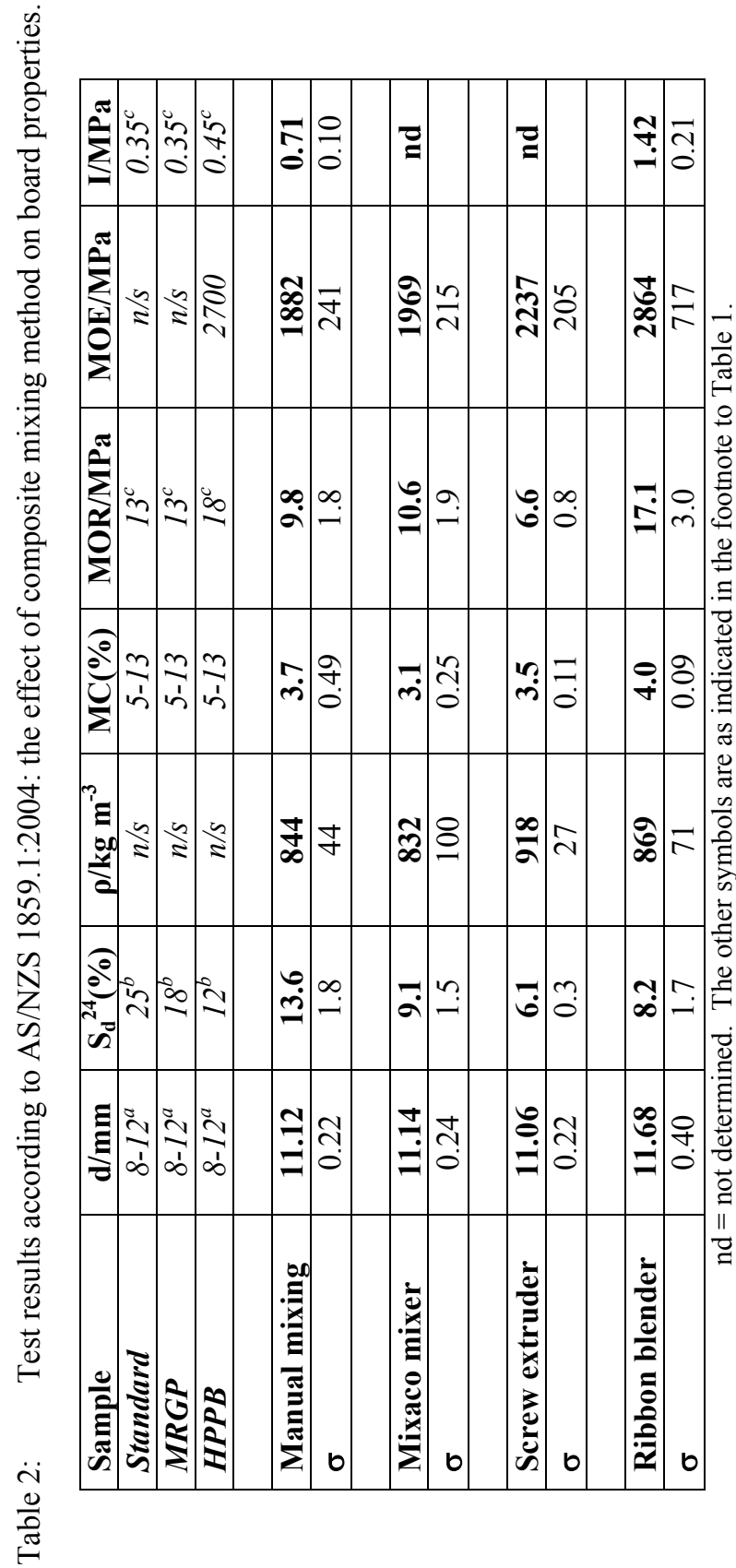




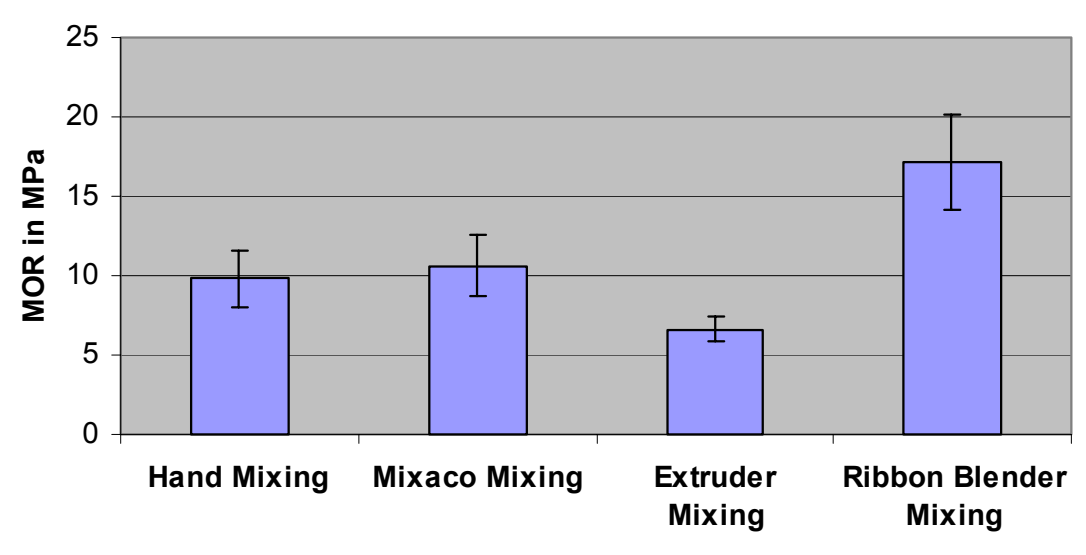

Figure 2: $\quad$ Effect of mixing method on the modulus of rupture of composite boards.

\subsection{Composite inter-phase characterization}

\subsubsection{Scanning electron microscopy}

The micrograph of the fracture surface produced in the internal bond test (Figure 3a) shows that the wood component was completely coated with the binders. The sawdust particles were in a flat oriented position due to the compression exerted during board making. Figure $3 \mathrm{~b}$ shows clearly fractured wood cells, indicating that sawdust particles were fractured rather than being pulled from the matrix.
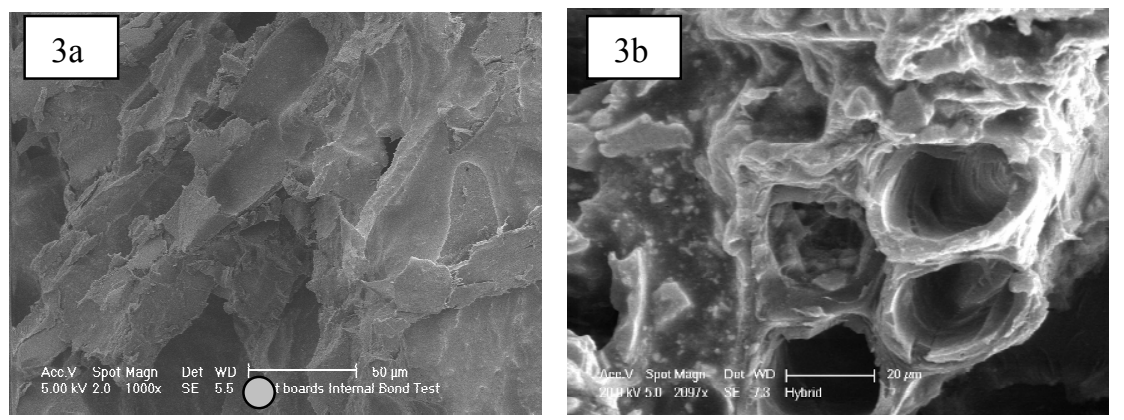

Figure 3: Scanning electron micrographs of fracture surfaces resulting from (a), internal bond strength test; (b), three point bend test.

\subsubsection{Thermal analysis}

All of the resin powders used in this study showed similar thermal properties (Table 3), melting in the range 55 to $100^{\circ} \mathrm{C}$. Glass transition temperatures $\left(\mathrm{T}_{\mathrm{g}}\right)$ were close to $45^{\circ} \mathrm{C}$ for the uncured powders, and curing increased $\mathrm{T}_{\mathrm{g}}$ to $60-70^{\circ} \mathrm{C}$. 
Isothermal heating at $160^{\circ} \mathrm{C}$ yields $\mathrm{T}_{\mathrm{g}}$ values that are mostly close to those of the fully cured powders. The glass transition temperatures of the boards were in most cases close to $T_{g}$ for the cured powders, indicating a high level of cure in the final products.

Table 3: $\quad$ Thermal characterisation (by DSC) of powder coating powders and fines.

\begin{tabular}{|l|l|l|l|l|}
\hline Resin sample & $\mathrm{T}_{\mathrm{g} 0}$ & $\mathrm{~T}_{\mathrm{g} 1}$ & $\mathrm{~T}_{\mathrm{g} 2}$ & $\mathrm{~T}_{\mathrm{gb}}$ \\
\hline HAA powder & 43 & 60 & 65 & $\sim 60.5$ \\
\hline TGIC powder & 46 & 69 & 70 & $\sim 66$ \\
\hline Hybrid powder & 42 & 67 & 68 & $\sim 63$ \\
\hline Fines & 42 & 57 & 62 & $\sim 59$ \\
\hline
\end{tabular}

$\mathrm{T}_{\mathrm{g} 0}=\mathrm{T}_{\mathrm{g}}$ for the uncured powders heated from $25^{\circ} \mathrm{C}$ to $250^{\circ} \mathrm{C} ; \mathrm{T}_{\mathrm{g} 1}=\mathrm{T}_{\mathrm{g}}$ after isothermal heating at $160^{\circ} \mathrm{C}$ for $10 \mathrm{~min}$.; $\mathrm{T}_{\mathrm{g} 2}=\mathrm{T}_{\mathrm{g}}$ after cyclic heating from $25^{\circ} \mathrm{C}$ to $250^{\circ} \mathrm{C}$, repeated after cooling to $25^{\circ} \mathrm{C} ; \mathrm{T}_{\mathrm{gb}}=\mathrm{T}_{\mathrm{g}}$ for boards after heating from $25^{\circ} \mathrm{C}$ to $250^{\circ} \mathrm{C}$.

\section{Conclusions}

From the results of this study it is apparent that composite boards can successfully be made from waste powder coating powders and fines. The boards meet relevant standard specifications, and their morphology suggests strong interaction between the resins and the cellulosic particles. The method of mixing is important in achieving the best strength characteristics of the boards, and composite mixing with ribbon blender is the most effective of the mixing methods used.

Being manufactured only from industrial waste materials, these composite boards are novel. Commercialization (Squire et al [8]) of this product will greatly reduce the amount of waste powder coating material that is disposed of in landfill.

\section{References}

[1] Graewe, R., Process for recycling powder coating waste, US Patent 6881762.

[2] Kilner, I., Process for recycling powder coating fines, GB Patent 6793163.

[3] Blatter, K., Montgomery, D., Bolm, H., Continuous method for reusing coating powder waste and coating powders thus obtained, in: US Patent 6500385 .

[4] Murray, B., A Novel Approach to the re-use of Powder Coating Fines, Paper presented at Powder Coating 2002 in Indianapolis, 2002.

[5] Anon, Aqueous Powder Systems, Finishing Industry vol. 5 (1982) pp. 2122.

[6] Wright, T., Chinacoat 2006. Coatings World, December, pp. 24-26, 2006. 
[7] Bledzki, A.K., Letman, M., Viksne, A., Rence, L., A comparison of compounding processes and wood type for wood fibre-PP composites. Composites Part A: Applied Science and Manufacturing 36 (6), pp. 789797, 2005.

[8] Squire, G.N., Abhyankar, A., Watson, K.J. Product and method of manufacture, NZ Patent Application 549170. 